\title{
Article
}

Mycosphere

\section{Study of the biological activities of Physarum polycephalum and Physarella oblonga plasmodial extracts}

\author{
Nguyen TN Nguyen ${ }^{1}$, Tuyen TM Huynh ${ }^{1}$, Steven L Stephenson ${ }^{2}$, Hanh TM Tran ${ }^{* 1}$ \\ ${ }^{1}$ School of Biotechnology, Ho Chi Minh International University, Thu Duc, Ho Chi Minh City, Vietnam \\ ${ }^{2}$ Department of Biological Sciences, University of Arkansas, Fayetteville, AR 72701, United States
}

Nguyen TN Nguyen, Tuyen TM Huynh, Steven L Stephenson, Hanh TM Tran 2017 - Study of the biological activities of Physarum polycephalum and Physarella oblonga plasmodial extracts. Mycosphere 8(7), 968-976, Doi 10.5943/mycosphere/8/7/12

\begin{abstract}
Various species of myxomycetes have been found to produce bioactive compounds that appear to considerable potential for pharmaceutical applications. However, obtaining a sufficient amount of sample material for studying the bioactive compounds of myxomycetes has been a real challenge due to the small size of their fruiting bodies in the field and the slow growth rates of their plasmodia on synthetic media under laboratory conditions. The research reported herein was carried out first to study the effects of carbon source and carbon concentration on the growth of Physarum polycephalum and Physarella oblonga and then to evaluate antimicrobial and anticancer activities of their plasmodial extracts. Physarella oblonga was found to grow better on agar without nutrients, as it has ability to hydrolyze agar as a carbon source. The best agar concentration for the growth of this species was $19 \mathrm{~g} / \mathrm{L}$, and at this concentration a remarkably high amount of plasmodia $(92.05 \mathrm{~g} / \mathrm{L})$ was obtained. In contrast, Physarum polycephalum preferred glucose as a carbon source, and $20 \mathrm{~g} / \mathrm{L}$ of glucose was found to be the most suitable amount for this species. At this gulcose concentration, $65.02 \mathrm{~g} / \mathrm{L}$ of plasmodia was produced. In term of antimicrobial activity, none of the Phy. oblonga extracts showed inhibitory activity on the pathogens tested. However, 90\% $\mathrm{MeOH}$ and 90\% $\mathrm{MeOH}: 90 \%$ acetone extracts of Ph. polycephalum showed antimicrobial activity toward Staphylococcus aureus. Data on the minimum inhibitory concentration (MIC) showed that $S$. aureus was more susceptible to the extract of $\mathrm{Ph}$. polycephalum $90 \% \mathrm{MeOH}: 90 \%$ acetone as the MIC of this extract was in the range of 1.56 to $0.78 \mathrm{mg} / \mathrm{mL}$, whereas that of the $90 \% \mathrm{MeOH}$ extract was between 6.25 and $3.12 \mathrm{mg} / \mathrm{mL}$. However, the minimum bactericidal concentration values of these two extracts were found to be the same (at $12.5 \mathrm{mg} / \mathrm{mL}$ ). Initially, studies of the cytotoxicity of the extracts found that Phy. oblonga extracts could inhibit the tested cancer cell lines better when compared to those of $P h$. polycephalum. Notably, MeOH:Chl Phy. oblonga had an inhibitory rate of $31.95 \pm 6.37 \%$ on Jurkat blood cancer cells.
\end{abstract}

Key words - Anticancer activity - Antimicrobial activity - Myxomycete plasmodial extracts - Jurkat cells - Staphylococcus aureus

\section{Introduction}

The myxomycetes (plasmodial slime molds or myxogastrids) are a small group of fungus-like organisms (Lado 2001) with a life cycle that includes two trophic (or feeding) stages. The first stage consists of uninucleate amoebae and the other a multinucleate structure called a plasmodium. The latter is essentially a very large cell that contains numerous nuclei without having cell walls (Martin 
et al. 1996). There are three distinct types of plasmodia produced by myxomycetes. These are the protoplasmodium, characteristic of members of the order Echinosteliales; the aphanoplasmodium, characteristic of members of the order Stemonitales; and the phaneroplasmodium, which is characteristic of members of the order Physarales (Gray \& Alexopoulos 1968, Keller \& Braun 1999). All three types of plasmodia are capable of movement and feed by migrating various distances within or on a given substrate. Under optimal environmental conditions, a plasmodium gives rise to one or more fruiting bodies containing spores. The phaneroplasmodium is the best-known and most easily studied type of plasmodium and has been the subject of numerous research projects. Phaneroplasmodia have rapid rates of growth and are relatively easy to culture under laboratory condition (Alexopoulos 1960).

More than 100 secondary metabolites have been isolated from myxomycetes (Dembitsky et al. 2005). Many crude extracts obtained from myxomycete fruiting bodies and plasmodia have shown antimicrobial and antitumor properties. A number of fatty acids and their derivatives are known for their antimicrobial activity (Ishibashi et al. 2001, Misono et al. 2003a, Nakatani et al. 2005). A new glycerolipid (bahiensol), isolated from a $90 \% \mathrm{MeOH}: 90 \%$ acetone crude extract obtained from the plasmodium of Didymium bahiense, displayed an inhibition zone $(12.5 \mathrm{~mm})$ toward Bacillus subtilis (Misono et al. 2003b). Stigmasterol and fatty acids purified from 95\% ethanol plasmodial extracts of Phy. oblonga showed positive activity against epymastigote forms of Trypanosoma cruzi. Moreover, a crude extract from Physarum melleum displayed growth inhibition of the phytopathogen Fusarium oxysporum (Herrera et al. 2011).

In addition, Herrera et al. (2011) indicated that an extract from an unidentified species of myxomycete showed strong antimicrobial and antifungal activities against isolated strains of Bacillus cereus, Fusarium oxysporum and Rhizoctonia solani, and Nakatani et al. (2005) reported that a 90\% $\mathrm{MeOH}$ and $90 \%$ acetone crude extract from Physarum melleum exhibited antimicrobial activity against Bacillus subtillis. In terms of anticancer activity, a 95\% ethanol extract of fresh Phy. oblonga plasmodial fractions was found to exhibit an inhibitory activity against approximately $22.7 \%$ of a Jurkat Lat GF cells population (Herrera et al. 2011). Arcyroxocin and a bisindole alkaloid isolated from a $90 \% \mathrm{MeOH}: 90 \%$ acetone extract obtained from the fruiting bodies of Arcyria denudata, together with dihydroarcyriacyanin A, obtained from 90\% MeOH:90\% acetone extract from Arcyria obvelata extract, showed antitumor activities against Jurkat cells (Kamata et al. 2006). Kehokorins A, a novel dibenzofuran, isolated from a $90 \% \mathrm{MeOH}: 90 \%$ acetone extract obtained from the fruiting bodies of Trichia favoginea var. persimilis displayed cytotoxic toward HeLa cells with an IC50 value of $1.5 \mu \mathrm{g} / \mathrm{mL}$ (Kaniwa et al. 2006). Moreover, cyclic phosphatidic acid (CPA), a novel bioactive lipid isolated from $\mathrm{Ph}$. polycephalum, showed specific biological functions, including antimitogenic regulation of the cell cycle, regulation of actin stress fiber formation and rearrangement, inhibition of cancer cell invasion and metastasis, regulation of differentiation and viability of neuronal cells, and mobilization of intracellular calcium (Murakami-Murofushi et al. 2002).

In addition, two new bisindole alkaloids isolated from a 90\% MeOH:90\% crude acetone extract from the fruiting bodies of Lycogala epidendrum showed cytotoxicity against HeLa cells and Jurkat cells with IC50 values of 5.4 and $2.1 \mu \mathrm{g} / \mathrm{mL}$, respectively. The alkaloids also had slightly weak cytotoxicity against vincristine resistant KB/VJ300 cells (Hosoya et al. 2005). Synthetic media with a sugar (e.g., glucose) or oat flakes as the carbon source has been commonly used for cultivation of several species of Physarum. However, from our observations, different species prefer different carbon sources and carbon concentrations. As such, the research described herein was carried out first to study the effects of carbon source and carbon concentration on the growth Ph. polycephalum and Phy. oblonga and then to evaluate antimicrobial and anticancer activities of their plasmodial extracts.

\section{Materials \& Methods}

\section{Myxomycete cultures}

The strain of $P h$. polycephalum used in the present study was obtained as a sclerotium from Carolina Biological Supply Company (Burlington, North Carolina, USA). Phy. oblonga was obtained 
from the myxomycete culture collection of the Applied Microbiology Labratory (School of Biotechnology, Ho Chi Minh International University, Ho Chi Minh city, Vietnam).

\section{Pathogenic microorganisms}

The pathogenic microorganisms Staphylococcus aureus ATCC 25213, Salmonella typhimurium ATCC 14028, Escherichia coli ATCC 25922 and Candida albicans ATCC 1413 were used for the antimicrobial tests.

\section{Cancer cell lines}

The human breast cancer MCF-7 cell line, the Cervical HeLa cancer cell line, the Jurkat blood cancer cell line and the human liver cancer cell line Hep-G2 were purchased from the American Type Culture Collection (Manassas, Rockville, Maryland, USA) by the Faculty of Biochemistry (Ho Chi Minh City University of Science, Ho Chi Minh City, Vietnam).

\section{Cultivation of myxomycete plasmodia}

Spore germination, sclerotial activation and inoculum preparation were carried out following Tran et al. (2012) and Tran et al. (2015). A piece of agar (about $2 \mathrm{~cm}^{2}$ ) bearing a portion of the active plasmodium growing on oat flakes was transferred from the inoculum culture to either a water agar or nutrient agar medium by using sterile blade and forceps. The cultures were inoculated in the dark at room temperature $\left(25^{\circ} \mathrm{C}\right)$ for 5 days, when the plasmodia developed fully on the plate. The plasmodia were collected and placed in sterile falcon tubes and freeze-dried using a standard freeze-drier device (Tran et al. 2012).

One liter of nutrient medium containing $100 \mathrm{~mL}$ of a basal salt solution, $5.0 \mathrm{~g}$ of glucose [Difco], $2.5 \mathrm{~g}$ of yeast extract [Difco], $15 \mathrm{~g}$ of Bacto agar, and $900 \mathrm{~mL}$ of distilled water adjusted to $\mathrm{pH} 5.5$ was used. The basal salt solution contained $29.78 \mathrm{~g}$ of citric acid, $33.10 \mathrm{~g}$ of $\mathrm{K}_{2} \mathrm{HPO}_{4}, 2.50 \mathrm{~g}$ of $\mathrm{NaCl}, 1.00 \mathrm{~g}$ of $\mathrm{MgSO}_{4} .7 \mathrm{H}_{2} \mathrm{O}, 0.50 \mathrm{~g}$ of $\mathrm{CaCl}_{2} .2 \mathrm{H}_{2} \mathrm{O}$, and $1000 \mathrm{~mL}$ distilled water (Henney \& Henney 1968).

\section{Effects of carbon source and carbon concentration on myxomycete plasmodial growths}

Preliminary studies showed that $P h$. polycephalum preferred glucose and Phy. oblonga grew better in water agar without glucose (Phy. oblonga has agar hydrolytic activity). Thus, different carbon sources were used for these two species.

To study the effects of glucose concentration on $\mathrm{Ph}$. polycephalum plasmodium culture, glucose with various concentrations ( 5 to $35 \mathrm{~g} / \mathrm{L}$ ) was used, whereas to study the effects of agar concentration on Phy. oblonga plasmodium culture, water agar was prepared with different amounts of agar (ranging from 10 to $25 \mathrm{~g} / \mathrm{L}$ ).

\section{Myxomycete plasmodial extract preparation}

A sample of freeze-dried plasmodial was ground to a fine powder for preparation of the extracts.

\section{Methanol:Chloroform (MeOH:Chl) extract}

The $\mathrm{MeOH}: \mathrm{Chl}$ plasmodium extract was prepared following the procedure outlined by Bligh \& Dyer (1959) with some minor modifications. One gram of dried plasmodium was homogenized with a methanol: chloroform (20:10, v/v) solution in a $35-\mathrm{mL}$ sterile glass vial. After 15 minutes, $5 \mathrm{~mL}$ water was added to each vial, the vial was gently vortexed and set aside until the separation of three different phases was formed $(5 \mathrm{~mL}$ chloroform was added in case there was no obvious separation observed). The lower phase of the mixture was transferred to another glass bottle and evaporated until a constant weight was obtained (Tran et al. 2012).

\section{0\% MeOH extract}

One gram of the dried plasmodium was added into a $35-\mathrm{mL}$ sterile glass vial containing $20 \mathrm{~mL}$ $90 \%$ methanol. This mixture was placed on a shaking incubator at room temperature for 12 hours. The 
homogenized solution was then collected and transferred to another vial. The methanol mixture was evaporated until completely dried (Kang et al. 2011).

\section{0\% methanol:90\% acetone extract}

One gram of dried myxomycete plasmodium was homogenized with a $90 \%$ methanol:90\% acetone $(20: 8, \mathrm{v} / \mathrm{v})$ solution in $35 \mathrm{~mL}$ sterile glass vial. After 30 minutes, $2 \mathrm{~mL}$ of $90 \% \mathrm{MeOH}$ and 0.8 $\mathrm{mL}$ hexane were added. The vial was set aside for another 30 minutes. The homogenized solution was then transferred to another glass vial. The extract was evaporated until completely dried (Misono et al. 2003b).

All of the dried extracts were dissolved in 2\% Dimethyl sulfoxide (DMSO) (100mg/mL) for microbial tests and the cytotoxic assay.

\section{Preparation of pathogenic microorganisms}

Three pathogenic bacteria were cultured in LB broth until the cultures reached the concentration of approximately 1-1.5 x $10^{8} \mathrm{CFU} / \mathrm{mL}$. Candida albicans was cultured in Sabouraud Dextrose (SD) broth until the fungal culture had reached approximately $1-1.5 \times 10^{8} \mathrm{CFU} / \mathrm{mL}$.

\section{Well diffusion method}

One hundred $\mu \mathrm{L}$ of the microorganism suspension was spread on either a LB or SD agar plate using sterile cotton swab. Four 8-millimeter diameter wells were made on each plate, and $100 \mu \mathrm{L}$ of the extract was added to two wells. Two remaining wells were used for positive and negative control. Gentamycine $(1 \mathrm{mg} / \mathrm{mL})$ and Ketoconazole $(0.4 \mathrm{mg} / \mathrm{mL})$ were used as positive antimicrobial controls for bacteria and fungus, respectively, whereas $2 \%$ DMSO was used as the negative control (Kang et al. 2011; Herrera et al. 2011). The plates were incubated at $37^{\circ} \mathrm{C}$ in $12-18$ hours for bacteria and 2436 hours for the fungal cultures. Diameters of the inhibition zone in millimeters (minus the well diameter) were recorded (Anesini et al. 1993, Azizkhani et al. 2013)

\section{Minimum inhibitory concentration (MIC) and minimum bactericidal concentration (MBC)}

The minimum inhibitory concentration (MIC) was carried out using the micro-titer broth dilution method (Hassan et al. 2011). The assay was performed in a sterile 96-well micro-titer plate. Two positive controls (medium and inoculum; $2 \%$ DMSO and inoculum) and two negative controls (extract and medium; $2 \%$ DMSO and medium) were included to obtain more accurate evaluations of the results.

Each treatment/well contained $100 \mu \mathrm{L}$ of broth medium and $100 \mu \mathrm{L}$ of standard bacteria inoculum $\left(10^{6} \mathrm{cfu} / \mathrm{mL}\right)$ and the plasmodial extract with a particular concentration (within the range of 25 to 0.39 $\mathrm{mg} / \mathrm{mL}$ ). The micro-titer plates were incubated at $37^{\circ} \mathrm{C}$ for $12-18$ hours. MICs were then recorded (Chanthaphon et al. 2008). As the extracts exhibited colors, MBC was investigated to confirm the MIC values. The $\mathrm{MBC}$ was the plate with the lowest concentration of extract which showed no evidence of microbial growth (Betts et al. 2012).

\section{Cytotoxic assay by Sulforhodamine B (SRB) assay}

The cell lines were cultured at $37^{\circ} \mathrm{C}$ and $5 \% \mathrm{CO}_{2}$ in Eagle's Minimal Essential Medium (EMEM) supplemented with $10 \%$ (v/v) FBS (Sigma), $2 \mathrm{mM}$ L-glutamine (Sigma), $20 \mathrm{mM}$ HEPES (Sigma), $0.025 \mu \mathrm{g} / \mathrm{mL}$ amphotericin B (Sigma), $100 \mathrm{IU} / \mathrm{mL}$ penicillin $\mathrm{G}$ (Sigma) and $100 \mu \mathrm{g} / \mathrm{mL}$ of streptomycin (Sigma) (Nguyen et al. 2016).

\section{SRB assay}

Cells seeded at a density of 10,000 cells/well in 96-well plates were cultured for $24 \mathrm{~h}$ before being incubated with the tested plasmodial extract for $48 \mathrm{~h}$. Treated cells were fixed with cold $50 \%$ (w/v) trichloroacetic acid (Merck) solution for 1-3 h, washed, and stained with $0.2 \%$ (w/v) SRB (Sigma) for $20 \mathrm{~min}$. After five washes with 1\% acetic acid (Merck), protein-bound dye was solubilized in $10 \mathrm{mM}$ Tris base solution (Promega). Optical density values were determined with a 96-well micro- 
titer plate reader (Synergy HT, Biotek Instruments) at the wavelengths of $492 \mathrm{~nm}$ and $620 \mathrm{~nm}$. The percentage of growth inhibition (Inh \%) was calculated according to the formula

$\operatorname{Inh}(\%)=(1-[\mathrm{ODt} / \mathrm{ODc}] \times 100) \%$

in which ODt and ODc are the optical density values of the test sample and the control sample, respectively. Camptothecin (Calbiochem) was used as the positive control (Nguyen et al. 2016).

\section{Experimental statistics}

All the experiments were carried out in triplicate. The results were reported as mean \pm standard deviation (SD). Statistical analysis of the data was conducted by analysis of variance (One-way ANOVA) using the Statistical Package for the Social Sciences (SPSS) software version 16.0. A probability value of $p \leq 0.05$ indicated a significant difference in the result of the particular test being carried out.

\section{Results and Discussion}

\section{Effects of carbon concentration on plasmodial growth of Phy. oblonga and Ph. polycephalum}

Phy. oblonga was observed to have agar-hydrolytic activity and could grow better on a water agar medium, which is different from other myxomycetes, including Ph. polycephalum. Therefore, agar and glucose were chosen as the carbon source for cultivation of Phy. oblonga and Ph. polycephalum, respectively. Effects of the carbon concentrations on the plasmodial cultures are shown in Fig. 1 and 2.



Fig. 1 - Effect of glucose concentrations on biomass production by $P h$. polycephalum

The fresh biomass production of $P h$. polycephalum was found to increase with increasing glucose concentrations from 15 to $35(\mathrm{~g} / \mathrm{L})$. Notably, the highest amount of biomass $(62.09 \mathrm{~g} / \mathrm{L})$ was recorded for a $20 \mathrm{~g} / \mathrm{L}$ glucose culture, which is significantly different when compared with the cultures with lower glucose concentrations. Since glucose is the main carbon source in the medium, higher glucose concentration could enhance plasmodial production. However, there was no significant difference in biomass production when glucose fell in the range from 20 to $30 \mathrm{~g} / \mathrm{L}$, and the plasmodial concentration decreased when the glucose was $35 \mathrm{~g} / \mathrm{L}$. It seems likely that the high concentrations of glucose would cause high osmotic pressure, and this would negatively affect plasmodial growth. For $P h$. polycephalum this effect began to become evident at $35 \mathrm{~g} / \mathrm{L}$. 


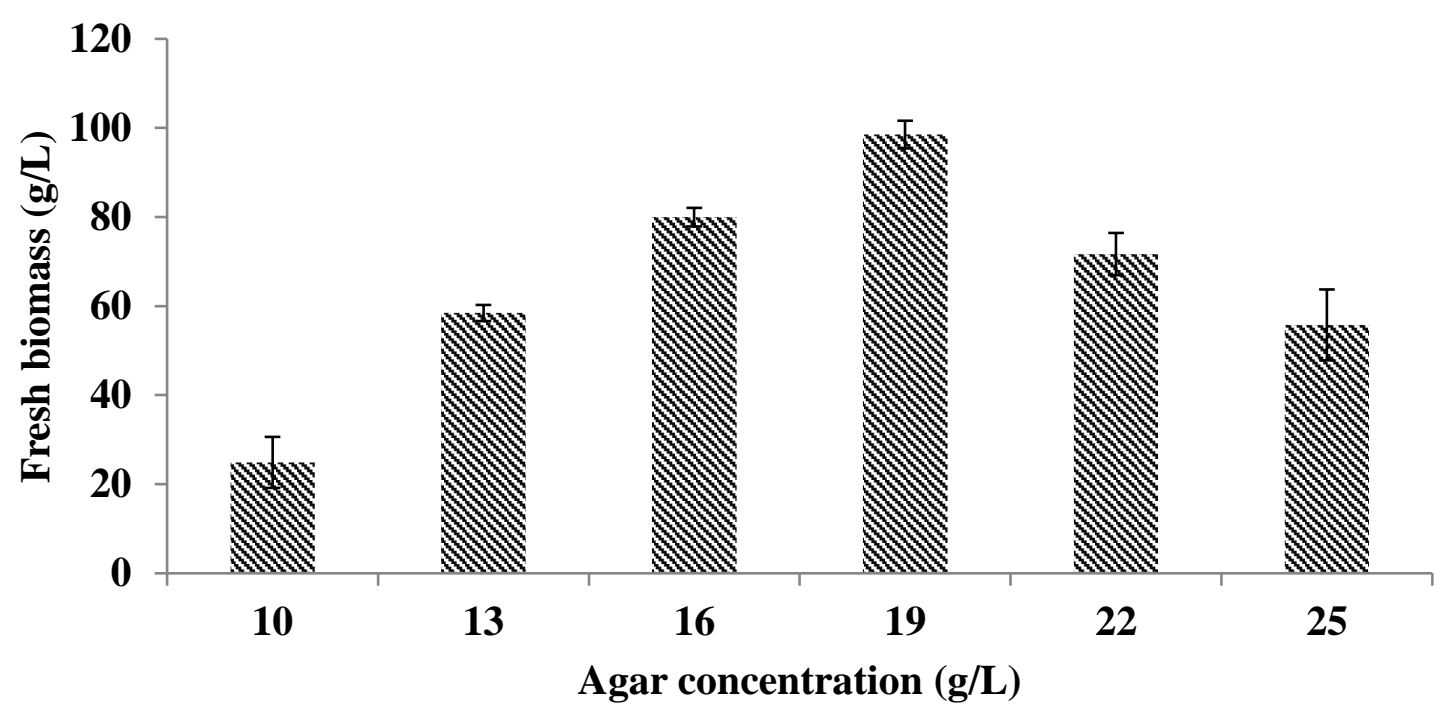

Fig. 2 - Effect of agar concentrations on biomass production of Phy. oblonga

As noted in Fig. 2, the biomass production of Phy. oblonga was found to increase when agar concentration was increased in increments from 16 to $19 \mathrm{~g} / \mathrm{L}$. The highest amount of fresh biomass $(98.5 \mathrm{~g} / \mathrm{L})$ was observed at $19 \mathrm{~g} / \mathrm{L}$. When the agar concentration exceeded $22 \mathrm{~g} / \mathrm{L}$, plasmodial production decreased. The lowest biomass production $(24.9 \mathrm{~g} / \mathrm{L})$ was obtained from the $10 \mathrm{~g} / \mathrm{L}$ agar culture. Because Phy. oblonga can utilize agar for as a carbon source, the higher agar concentration would be expected. In addition, higher agar concentration also increased the firmness of agar surface, which would help Phy. oblonga plasmodia easily to expand. The negative effects recorded from cultures with $25 \mathrm{~g} / \mathrm{L}$ of agar would be explained by the fact that when the concentration of agar is too high, the availability of water in the culture decreased. This made the agar crack; moreover, the lack of water would negatively affect the metabolic activities of plasmodia. However, a low concentration of agar, which would result in high water content in the culture, also would make it difficult for a plasmodium to obtain oxygen because the water could cover the plasmodium, resulting in poor biomass production (Tran et al. 2015)

\section{Primary study on antimicrobial activities of Phy. oblonga and Ph. polycephalum extracts}

Antimicrobial activity of Phy. oblonga and Ph. polycephalum plasmodial extracts was primarily determined by the well diffusion method. The antimicrobial activity was assessed by determining the diameter (in $\mathrm{mm}$ ) of the growth inhibition zone and showed in Table 1.

In general, only the $90 \% \mathrm{MeOH}: 90 \%$ acetone and $90 \% \mathrm{MeOH}$ extracts of Ph. polycephalum were found to have antimicrobial activities. The extracts showed inhibitory activities toward S. aureus, for which the inhibition zone diameters were $15 \pm 1.5 \mathrm{~mm}$ and $5 \pm 1 \mathrm{~mm}$, respectively.

Thus, far, the ability of extracts obtained from $P h$. polycephalum has not been reported in the literature. In the present study, although $S$. aureus was susceptible to the $P h$. polycephalum extracts, it should be noted that after 36 hours, $S$. aureus grew back into the inhibition zones, causing the zones to become smaller. However, since the extracts were crude, the amount of the actual antimicrobial compounds present would be expected to be rather low.

Phy. oblonga in our research did not exhibit any antimicrobial activity. It seems likely that different species of myxomycetes species display different types and levels of biological activity, which may be the result of their individual strategies to cope with the different biotic components of their environment (Herrera et al. 2011).

Since $\mathrm{Ph}$. polycephalum extracts (90\% MeOH:90\% acetone and $90 \% \mathrm{MeOH}$ ) displayed antibacterial activities toward $S$. aureus, MICs of the extracts against this gram-positive bacterium were determined and the results are shown in Table 2.

MIC results showed that $S$. aureus was more susceptible to the Ph. polycephalum $90 \% \mathrm{MeOH}$ : $90 \%$ acetone extract in the concentration range of 1.56 to $0.78 \mathrm{mg} / \mathrm{mL}$, whereas with the $90 \% \mathrm{MeOH}$ 
extract, the MIC value was between 6.25 to $3.12 \mathrm{mg} / \mathrm{mL}$. The MBC values of the two types of $P h$. polycephalum extracts were found to be the same $(12.5 \mathrm{mg} / \mathrm{mL})$.

Table 1 Antimicrobial activities of myxomycete plasmodial extracts

\begin{tabular}{|c|c|c|c|c|c|c|c|c|c|}
\hline \multirow[t]{2}{*}{ Test pathogen } & \multicolumn{3}{|c|}{ Ph.polycephalum } & \multicolumn{3}{|c|}{ Phy. oblonga } & \multicolumn{3}{|c|}{ Control } \\
\hline & $\begin{array}{c}\mathrm{ME} \\
\mathrm{a}\end{array}$ & $\begin{array}{c}\text { ME- } \\
\text { C }^{\text {a }}\end{array}$ & $\begin{array}{c}\text { ME- } \\
\mathbf{A}^{\mathrm{a}}\end{array}$ & $\begin{array}{c}\text { ME } \\
\text { a }\end{array}$ & $\begin{array}{c}\text { ME- } \\
\text { C }^{\text {a }}\end{array}$ & $\begin{array}{c}\text { ME- } \\
\mathbf{A}^{\mathrm{a}}\end{array}$ & $\mathbf{G}^{\mathbf{b}}$ & $\mathbf{K}^{\mathbf{c}}$ & $\begin{array}{c}2 \% \\
\text { DMSO }\end{array}$ \\
\hline S. aureus & + & - & +++ & - & - & - & $\begin{array}{c}+++ \\
+\end{array}$ & - & - \\
\hline E. coli & - & - & - & - & - & - & $\begin{array}{c}+++ \\
+\end{array}$ & - & - \\
\hline S. typhi & - & - & - & - & - & - & $\begin{array}{c}+++ \\
+\end{array}$ & - & - \\
\hline C. albican & - & - & - & - & - & - & - & $\begin{array}{c}+++ \\
+\end{array}$ & - \\
\hline
\end{tabular}

Notes: ME: 90\% MeOH extract, ME-C: MeOH:Chl extract, ME-A: 90\% MeOH: 90\% Acetone extract, G: Gentamycine, K: Ketoconaole. ${ }^{\mathrm{a}, \mathrm{b}, \mathrm{c}}$ concentration of $100 \mathrm{mg} / \mathrm{mL}, 1 \mathrm{mg} / \mathrm{mL}, 0.4 \mathrm{mg} / \mathrm{mL}$, respectively. [-] no inhibition zone, [+] inhibition zone less than $10 \mathrm{~mm},[++]$ inhibition zone from 10 to less than $15 \mathrm{~mm},[+++]$ inhibition zone from 15 to less than $20 \mathrm{~mm},[++++]$ inhibition zone greater than $20 \mathrm{~mm}$.

Table 2 Minimum inhibitory concentration $(\mathrm{mg} / \mathrm{mL})$ of $P h$. polycephalum extracts

\begin{tabular}{lcc}
\hline Extract & MIC $(\mathbf{m g} / \mathbf{m L})$ & MBC $(\mathbf{m g} / \mathbf{m L})$ \\
\hline 90\%MeOH:90\%Acetone & 0.78 & 12.5 \\
$90 \% \mathrm{MeOH}$ & 3.12 & 12.5 \\
\hline
\end{tabular}

\section{Cytotoxicity of Phy. oblonga and Ph. polycephalum extracts}

The extracts of Phy. oblonga and Ph. polycephalum were dissolved in absolute DMSO to reach the concentration of $100 \mu \mathrm{g} / \mathrm{mL}$ and tested with different cancer cell lines. The results obtained are displayed in Table 3.

As a general observation, $\mathrm{MeOH}: \mathrm{Chl}$ and $90 \% \mathrm{MeOH}: 90 \%$ acetone extracts of Phy. oblonga were observed to have inhibitory activities against the cancer cell lines tested in the present study, especially toward Jurkat cells. At a concentration of $100 \mu \mathrm{g} / \mathrm{mL}$, the $\mathrm{MeOH}$ :Chl extract from Phy. oblonga could inhibit Jurkat, MCF-7, Hep-G2 cancer cell lines with the rates of $31.95 \%, 12.02 \%$ and $11.33 \%$, respectively. The $90 \% \mathrm{MeOH}: 90 \%$ acetone extract from Phy. oblonga also showed cytotoxic city against Jurkat cancer cell lines, with a rate of $26.15 \%$. The Ph. polycephalum MeOH:Chl extract was toxic only on the Jurkat cell line with a rate of $13.26 \pm 3.43$.

Percentage inhibition of Jurkat Lat GF cells by the $90 \%$ ethanol Phy. oblonga extract as reported from previous studies was $22.7 \%$ (Herrera et al. 2011). In term of cytotoxicity of the $90 \% \mathrm{MeOH}: 90 \%$ acetone extract involving other species of myxomycetes, we are aware only of research on Trichia favoginea var. persimilis, in which the crude extract obtained from fruiting bodies was reported to inhibit $50 \%$ of the HeLa cells at $1.5 \mu \mathrm{g} / \mathrm{mL}$ (Kaniwa et al. 2006). This extract concentration is quite low compared with the concentration used in the present study.

\section{Conclusions}

Different species of myxomycetes require different optimized medium compositions for their growth. Glucose with a concentration of $20 \mathrm{~g} / \mathrm{L}$ was optimal for Ph. polycephalum, whereas $19 \mathrm{~g} / \mathrm{L}$ of agar was optimal for Phy. oblonga. In term of microbial activity, 90\% $\mathrm{MeOH}: 90 \%$ acetone and $90 \%$ $\mathrm{MeOH}$ extracts of $\mathrm{Ph}$. polycephalum displayed inhibitory activities toward S. aureus. Moreover, a 
preliminary investigation of the cytotoxicity of these extracts found that the $\mathrm{MeOH}: \mathrm{Chl}$ extract from Phy. oblonga displayed the potential to inhibit the Jurkat cell line.

Table 3 Cytotoxicity of Phy. oblonga and Ph. polycephalum extracts on various cancer cell lines (\%)

\begin{tabular}{|c|c|c|c|c|}
\hline \multirow{2}{*}{$\begin{array}{c}\text { Types of extracts } \\
(100 \mu \mathrm{g} / \mathrm{mL})\end{array}$} & \multicolumn{4}{|c|}{ Cytotoxicity on cancer cell lines (\%) } \\
\hline & MCF-7 & HeLa & Jurkat & Hep-G2 \\
\hline $\begin{array}{l}\text { Phy. oblonga } \\
\text { MeOH: Chl }\end{array}$ & $12.02 \pm 0.69$ & $-0.09 \pm 3.16$ & $31.95 \pm 6.37$ & $11.33 \pm 1.11$ \\
\hline $\begin{array}{l}\text { Ph. polycephalum } \\
\text { MeOH:Chl }\end{array}$ & $0.60 \pm 0.95$ & $-6.57 \pm 4.61$ & $13.26 \pm 3.43$ & $-0.43 \pm 2.67$ \\
\hline $\begin{array}{l}\text { Ph. polycephalum } \\
90 \% \mathrm{MeOH}: \quad 90 \% \\
\text { acetone }\end{array}$ & $-11.31 \pm 3.29$ & $3.84 \pm 3.56$ & $4.94 \pm 4.23$ & $-13.89 \pm 1.65$ \\
\hline $\begin{array}{l}\text { Phy. oblonga } \\
90 \% \quad \mathrm{MeOH}: \quad 90 \% \\
\text { acetone }\end{array}$ & $-6.86 \pm 4.07$ & $2.85 \pm 4.97$ & $26.15 \pm 3.10$ & $10.41 \pm 3.29$ \\
\hline $\begin{array}{l}\text { Ph. polycephalum } \\
90 \% \mathrm{MeOH}\end{array}$ & $-11.67 \pm 0.96$ & $4.80 \pm 5.51$ & $-1.02 \pm 6.57$ & $-31.22 \pm 2.48$ \\
\hline $\begin{array}{l}\text { Phy. oblonga } \\
90 \% \mathrm{MeOH}\end{array}$ & $5.82 \pm 5.23$ & $6.83 \pm 3.67$ & $9.88 \pm 0.17$ & $-4.93 \pm 3.90$ \\
\hline
\end{tabular}

Note: the minus figures indicate that the extracts stimulated the growth of the cells.

\section{Acknowledgements}

This research is funded by the Vietnam National Foundation for Science and Technology Development (NAFOSTED) under grant number 106-NN.04-2015.16.

\section{References}

Alexopoulos CJ. 1960 - Gross morphology of the plasmodium and its possible significance in the relationships among the Myxomycetes. Mycologia 52, 1-20.

Anesini C, Perez C. 1993 - Screening of plants used in Argentine folk medicine for antimicrobial activity. Journal of Ethnopharmacology 39, 119-128.

Azizkhani M, Misaghi A, Basti AA, Gandomi H, Hosseini H. 2013 - Effects of Zataria multiflora Boiss. essential oil on growth and gene expression of enterotoxins A, C and E in Staphylococcus aureus ATCC 29213. International Journal of Food Microbiology 163, 159-165.

Betts J, Murphy C, Kelly S, Hasweel S. 2012 - Minimum inhibitory and bactericidal concentrations of theaflavin and syngergistic combinations with epicatechin and quercetin against clinical isolates of Stenotrophomonas maltophilia. The Journal of Microbiology, Biotechnology and Food Sciences 1, 1250-1258.

Bligh EG, Dyer WJ. 1959 - A rapid method of total lipid extraction and purification. Canadian Journal of Biochemistry and Physiology 37, 911-917.

Chanthaphon S, Chanthachum S, Hongpattarakere T. 2008 - Antimicrobial activities of essential oils and crude extracts from tropical Citrus spp. against food-related microorganisms. Sonklanakarin Journal of Science and Technology 30, 125-131. 
Dembitsky VM, Řezanka T, Spížek J, Hanuš LO. 2005 - Secondary metabolites of slime molds. Phytochemistry 66, 747-769.

Gray WD, Alexopoulos CJ. 1968 - Biology of the Myxomycetes. Biology of the Myxomycètes.

Hassan M, Javadzadeh Y, Lotfipour F, Badomchi R. 2011 - Determination of comparative minimum inhibitory concentration (MIC) of bacteriocins produced by enterococci for selected isolates of multi-antibiotic resistant Enterococcus spp. Advanced Pharmaceutical Bulletin 1, 75-79.

Henney JHR, Henney MR. 1968 - Nutritional requirements for the growth in pure culture of the myxomycete Physarum rigidum and related species. Microbiology 53, 333-339.

Herrera NA, Rojas C, Franco-Molano AE, Stephenson SL, Echeverri F. 2011 - Physarella oblonga centered bioassays for testing the biological activity of myxomycetes. Mycosphere 2, 637-644.

Hosoya T, Yamamoto Y, Uehara Y, Hayashi M et al. 2005 - New cytotoxic bisindole alkaloids with protein tyrosine kinase inhibitory activity from a myxomycete Lycogala epidendrum. Bioorganic \& Medicinal Chemistry Letters 15, 2776-2780.

Ishibashi, M., Iwasaki, T., Imai, S., Sakamoto, S. et al. 2001. Laboratory culture of the Myxomycetes: formation of fruiting bodies of Didymium bahiense and its plasmodial production of makaluvamine A. Journal of Natural Products, 64, 108-110.

Kamata K, Suetsugu T, Yamamoto Y, Hayashi M et al. 2006 - Bisindole alkaloids from Myxomycetes Arcyria denudata and Arcyria obvelata. Journal of Natural Products 69, 1252-1254.

Kaniwa K, Ohtsuki T, Yamamoto Y, Ishibashi M. 2006 - Kehokorins A-C, novel cytotoxic dibenzofurans isolated from the myxomycete Trichia favoginea var. persimilis. Tetrahedron Letters 47, 1505-1508.

Kang GG, Hah DS, Kim CH, Kim YH et al. 2011 - Evaluation of antimicrobial activity of the methanol extracts from 8 traditional medicinal plants. Toxicological Research 27, 31-36.

Keller HW, Braun KL. 1999 - Myxomycetes of Ohio: their systematics, biology, and use in teaching. Ohio Biological Survey 12(3).

Lado C. 2001 - Nomenmyx: a nomenclatural taxabase of myxomycetes. Editorial CSIC-CSIC Press.

Martin GW, Alexopoulos CJ, Farr ML. 1996 - The genera of Myxomycetes. University of Iowa 20(8).

Misono Y, I shikawa Y, Yamamoto Y, Hayashi M et al. 2003a -Dihydrolindbladiones, three new naphthoquinone pigments from a myxomycete Lindbladia tubulina. Journal of Natural Products 66, 999-1001.

Misono Y, Ishibashi M, Ito A. 2003b - Bahiensol, a new glycerolipid from a cultured myxomycete Didymium bahiense var. bahiense. Chemical and Pharmaceutical Bulletin 51, 612-613.

Murakami-Murofushi K, Uchiyama A, Fujiwara Y et al.. 2002 - Biological functions of a novel lipid mediator, cyclic phosphatidic acid. Biochimica et Biophysica Acta (BBA)-Molecular and Cell Biology of Lipids 1582, 1-7.

Nakatani S, Kamata K, Sato M, Onuki H et al. 2005 - Melleumin A, a novel peptide lactone isolated from the cultured myxomycete Physarum melleum. Tetrahedron Letters 46, 267-271.

Nguyen MNT, Ho-Huynh TD. 2016 - Selective cytotoxicity of a Vietnamese traditional formula, Nam Dia long, against MCF-7 cells by synergistic effects. BMC Complementary and Alternative Medicine 16, 220.

Tran HTM, Stephenson SL, Chen Z, Pollock E D, Goggin FL. 2012 - Evaluating the potential use of myxomycetes as a source of lipids for biodiesel production. Bioresource Technology 123, 386389.

Tran H, Stephenson S, Pollock E. 2015 - Evaluation of Physarum polycephalum plasmodial growth and lipid production using rice bran as a carbon source. BMC Biotechnology 15, 67. 